\title{
Water pulsating heat pipe
}

\author{
Viacheslav Cheverda ${ }^{1,2, *}$, and Fedor Ronshin ${ }^{1,2}$ \\ ${ }^{1}$ Kutateladze Institute of Thermophysics SB RAS, 630090, Novosibirsk, Russia \\ ${ }^{2}$ Novosibirsk State University, 630090, Novosibirsk, Russia
}

\begin{abstract}
The new experimental setup with copper-glass pulsating heat pipe has been constructed for investigation of the heat transfer problem. Pulsations of liquid slugs inside the heat pipe has been observed. It is demonstrated that with increasing of temperature difference between evaporator and condenser heat flux which can be removed is also increases.
\end{abstract}

\section{Introduction}

Heat pipes are a promising cooling system due to the fact of non-availability of moving parts, for example, pumps. There are three main types of these devices: conventional heat pipes, loop heat pipes and pulsating heat pipes [1].

Pulsating heat pipes (PHPs) - a few connected tubes (or minichannels in the material), partially filled with liquid. The concept of PHP was introduced by Akachi $[2,3]$. PHPs have already found many applications in micro and power electronics applications owing to the unique operational characteristics coupled with relatively low costs. There are three main types of PHPs: closed, open and closed with a valve. In PHP, there is a region where heat is supplied, an adiabatic zone and a zone that is cooled [4]. Transport of heat is observed due to pulsations of liquid and vapor bubbles in the heat pipe. The thermodynamic principle of PHP is based on the absorption / rejection of heat by the liquid and thus by the growth / decrease of vapor bubbles, which is the driving force. So, in [5] the thermodynamics of the process was studied in more details on the pressure-enthalpy diagram.

Analysis of the temperature fluctuation in the experimental PHP showed that the oscillation is not periodic. Miyazaki and Akachi [6] used a closed-loop copper PHP filled with R142b, with 60 turns and at three different angles of inclination and variable filling. It was noted that the filling factor had a significant effect on the functioning of the PHP. The optimum filling with the condition of top heating is 35\%. Nishio [7] conducted experiments with glass PHP with different working liquids, internal diameters and aspectual ratio. It was found that the heat transfer coefficient between the wall and the working liquid is independent of the temperature difference between the evaporator and the condenser for filling from $30 \%$ to $80 \%$. Four liquids were tested (water, soap solution, ethanol and $\mathrm{R} 141 \mathrm{~b}$ ), for water the best results were obtained when the filling is equal to $30 \%$.

\footnotetext{
* Corresponding author: slava.cheverda@gmail.com
} 
The aim of the present work is to study the heat transfer processes in closed loop pulsating heat pipe.

\section{Experimental setup}

To study the heat transfer processes in closed loop pulsating heat pipe, a new experimental setup was created. The scheme and photo of the test cell are shown in Fig. 1. The working area consists of two parts: an evaporator and a condenser. Both are made of aluminum with dimensions of $40 \mathrm{~mm} \times 40 \mathrm{~mm} \times 424 \mathrm{~mm}$. In the condenser there are channels for pumping the coolant (water). The liquid is pumped through the condenser at a constant temperature using a thermostat LOIP FT-211-25.

To the
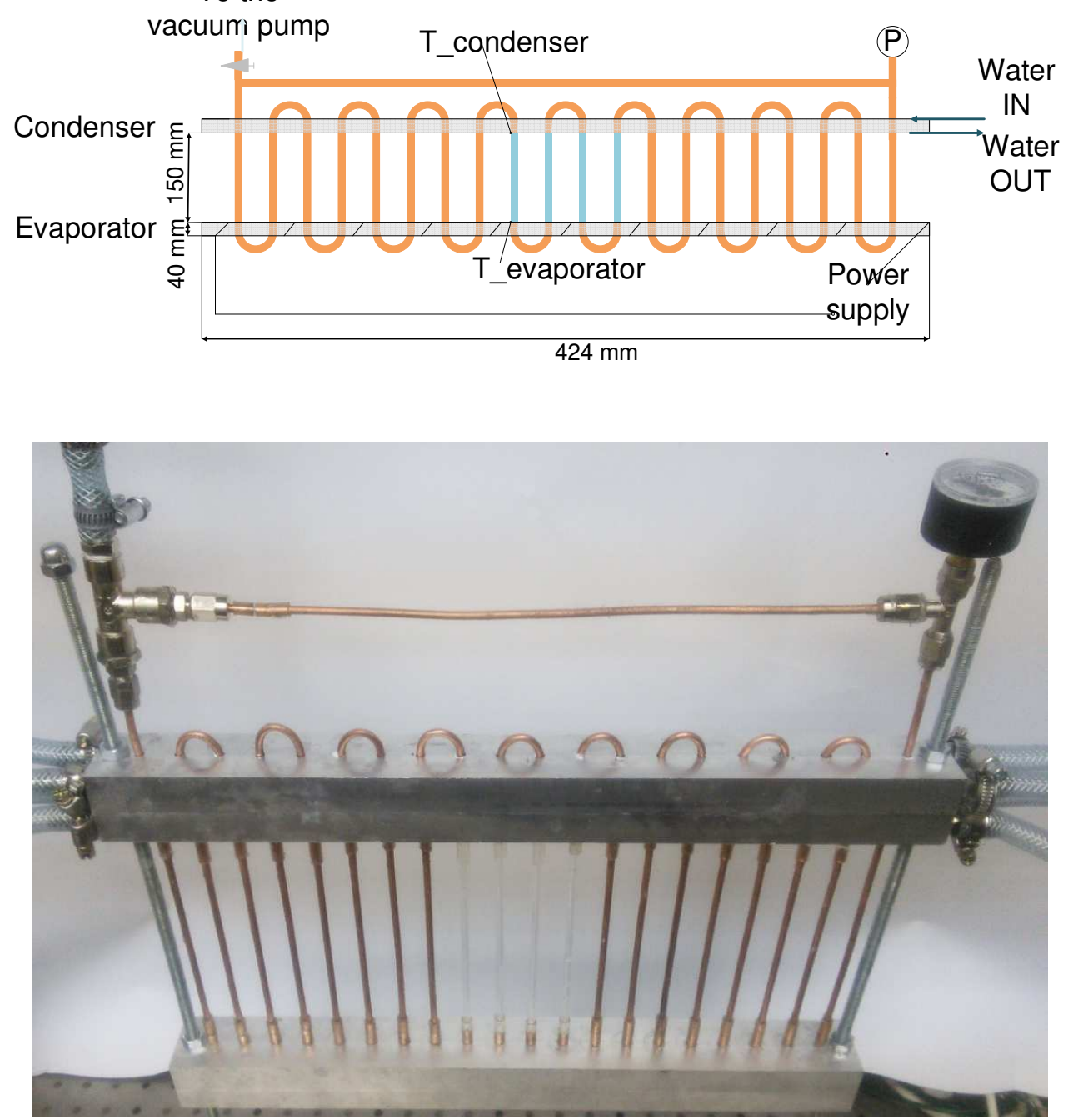

Figure 1. The scheme and photo of pulsating heat pipe. 
The evaporation part is heated by wire heater (constantan wire) and the power supply TTi QPX1200SP (1.2 kW). The PHP is made of ten cooper U-turns, where two of them in the evaporator and condenser zones coupled with fore glass tubes forming the adiabatic section. The internal diameter of the tube is $2 \mathrm{~mm}$, outer diameter is $4 \mathrm{~mm}$, and length is $150 \mathrm{~mm}$. With the help of a vacuum pump, air inside the tube was completely evacuated, and then a necessary portion of distilled and degassed water was pumped into it. All experiments with this set-up have been done with filling of water about 50\%. The pressure in the system has been measured using a manometer and pressure sensor WIKA Type P-30. The temperatures inside the condenser and evaporator were measured using two thermocouples K-type. The temperature and pressure data were recorded using a National Instruments data acquisition system and LabView software.

\section{Results and discussion}

After the evacuation and filling of the heat pipe, the first tests were carried out. The temperature of the condenser was maintained by means of a thermostat at a constant temperature of $24^{\circ} \mathrm{C}$. When the thermal power was enough to evaporate liquid at given pressure, pulsations of liquid in the heat pipe were observed. The graph of the temperature difference versus the heat output is shown in Fig.2. When the liquid evaporates in the evaporator zone, the pressure increases. At the same time in the condenser zone, the liquid condenses and the pressure drops. Due to the pressure difference, liquid is transported from the evaporator zone to the condenser zone. When the PHP works, we observe moving slugs. Periodically slugs change the direction of movement, forming pulsations.

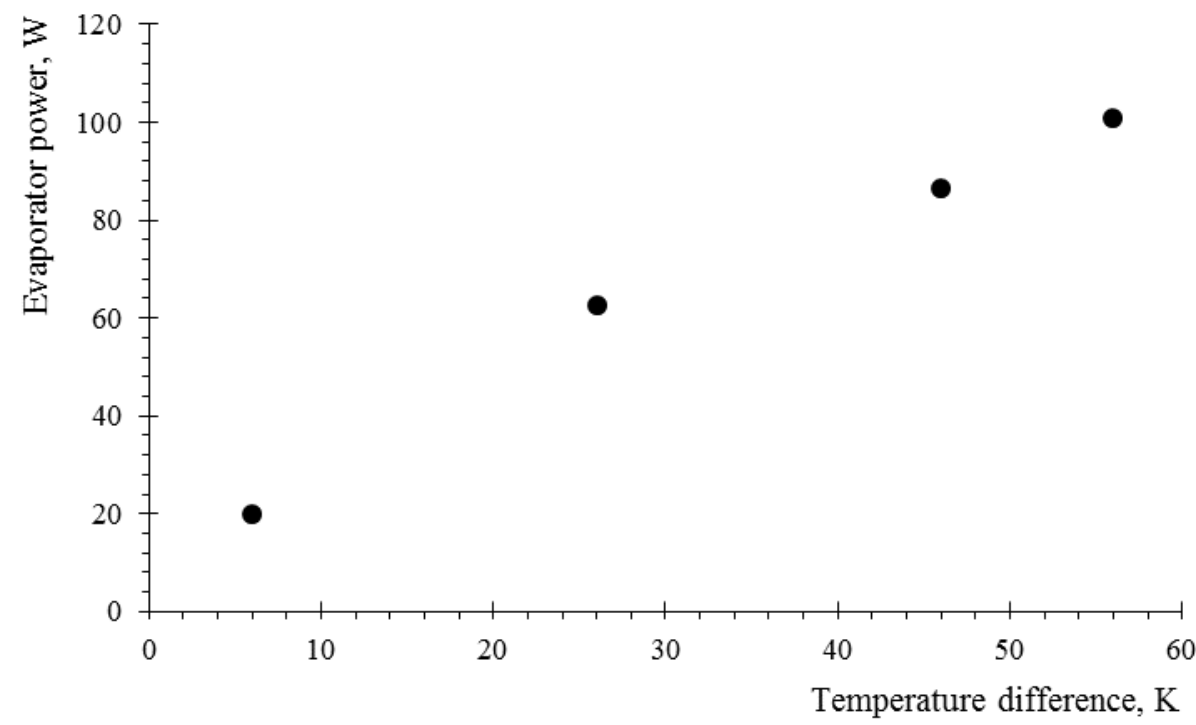

Figure 2. Power of PHP versus temperature difference. 


\section{Conclusions}

The copper-glass pulsating heat pipe has been constructed for investigation of the heat transfer problem in such devices. The first test experiments with a pulsating heat pipe with water were carried out. It is established that pulsations of liquid slugs begin when the tube is heated with power more than $20 \mathrm{~W}$. In the future, it is planned to use sapphire tubes instead of glass ones to determine the water temperature by infrared camera.

This work was financially supported by the Ministry of Education and Science of the Russian Federation (Agreement 14.613.21.0067, Project Identifier RFMEFI61317X0067).

\section{References}

1. Chaudhry HN, Hughes BR, Ghani SA., Renew Sustain Energy Rev, 16, p. 2249-59, (2012).

2. Akachi H., U. S. patent, Patent Number 4921041, (1990).

3. Akachi H., U. S. patent, Patent Number 5219020, (1993).

4. Zhang,Y., and Faghri, A., AIAA Journal of Thermophysics and Heat Transfer, 17, p. 755-764. (2003).

5. Groll, M., and Khandekar, S. Proc. International Conference on Energy and the Environment, Shanghai, China, 1, p. 723-730, (2003).

6. Miyazaki, Y., and Akachi, H., Proc. 5th International Heat Pipe Symposium, Melbourne, Australia, p. 378-383, (1996).

7. Nishio, S., Proc. 11th International Heat Pipe Conference, Tokyo, Japan, 2, p. 39-49, (1999). 